\title{
Personnel F
}

The Impact of COVID-19 on the Work-Life Balance of Working Mothers: Evidence from Nigerian Academics

\begin{tabular}{|r|l|}
\hline Journal: & Personnel Review \\
\hline Manuscript ID & PR-08-2020-0636.R2 \\
\hline Manuscript Type: & Research Article \\
\hline Keywords: & $\begin{array}{l}\text { Nigerian academics, Working Mothers, Work-Life Balance, Spread of } \\
\text { COVID-19 }\end{array}$ \\
\hline Methodologies: & Qualitative \\
\hline
\end{tabular}




\title{
The Impact of COVID-19 on the Work-Life Balance of Working Mothers: Evidence from Nigerian Academics
}

\begin{abstract}
Purpose - Given the limiting gender role conditions arising from the prevalence of patriarchy in Nigeria and the shift to workers staying at home due to the deadly spread of COVID-19, this article explores the impact of the COVID-19 pandemic on the work-life balance of professional mothers using the work-home resources model as a conceptual lens.

Design/methodology/approach - The qualitative data is based on telephone interviews with 28 married female university academics with children.

Findings - Our findings reveal that the confinement policies enforced due to the need to combat the spread of COVID-19 and patriarchal norms deeply embedded in the Nigerian culture have exacerbated stress among women, who have needed to perform significantly more housework and childcare demands alongside working remotely than they did prior to the pandemic. The thematic analysis showed a loss of personal resources (e.g. time, energy, and income) resulting in career stagnation, health concerns, and increased male chauvinism due to the abrupt and drastic changes shaping the 'new normal' lifestyle.
\end{abstract}

Research limitations/implications - The study relies on a limited qualitative sample size, which makes the generalisation of findings difficult. However, the study contributes to the emerging global discourse on the profound negative consequences of COVID-19 on the lives and livelihoods of millions, with a focus on the stress and work-family challenges confronting women in a society that is not particularly egalitarian - unlike western cultures.

Originality/value - The article provides valuable insights on how the COVID-19 pandemic has dramatically affected professional working mothers in the Sub-Saharan African context, where literature is scarce.

\section{Introduction}

The first documented outbreak of the deadly coronavirus (COVID-19) among humans was reported in Wuhan, Hubei Province, China in December 2019 (Chen and Li, 2020). At the time this article was completed and submitted for potential publication to Personnel Review on 24 August 2020, more than 23 million cases of COVID-19 had been reported in over 195 countries and territories, resulting in more than 800,000 fatalities - mostly recorded in Europe, North America, and Latin America (John Hopkins University Coronavirus Resource Center, 2020). The deadly disease, which is characterised by severe acute respiratory syndrome, primarily spreads by close contact between persons, while the world is battling to find a permanent cure and/or develop herd of immunity against the highly contagious virus (World Health Organization, 2020). Multiple preventive measures, such as social distancing, self-isolation, and travel restrictions, have led to a reduced workforce and have caused many job losses across the world. There have also been widespread chain supply shortages exacerbated by panic buying (Nicola et al., 2020). Schools, colleges, and universities were closed either on a national or local basis in almost 195 countries, affecting approximately $97.5 \%$ of the world's student population (Elliot, 2020). Consequently, COVID-19 is adversely affecting the work-life balance (WLB) of millions - and workers in the educational sector are no exception. 
For university academics, the compulsory 'stay-at-home' policies enforced by many nations have resulted in a drastic change from working in an office to working from home, leading to an unprecedented transition from the traditional face-to-face classroom learning to online education (Bao, 2020). Thus, Nash and Churchill (2020) reported emerging evidence from global media suggesting that female academics with care responsibilities have been severely affected, as they are struggling to work remotely and fulfil their mandatory role as the primary caregivers in their homes. In Nigeria, the escalating number of deaths due to the spike of COVID-19 also forced the closure of all higher education institutions and a switch in focus to online teaching. While Nigerian university lecturers are grappling with a serious economic recession due to the spread of COVID-19, it is worth exploring how working mothers in academia are being disproportionately affected as a result of the masculine hegemony that shapes gender roles in Nigeria, which is an area on which literature is scarce (Akanji et al., 2020). According to Adisa and Isaika (2019, p. 21), patriarchy is a social and ideological construct that considers men as superior to women in all spheres of life and perpetuates gender inequality, sexism, and the subordination of women. This situation perpetuates extreme role overload particularly for working mothers in white collar professions, specifically in the global south (Mordi et al., 2013). Similarly, gender stereotypes resulting from long-standing patriarchal values from Asian contexts such as Japan is exacerbated by their Confucian culture which propagates adherence of women to familial roles and structures irrespective of their active labour involvement in the knowledge-based economy (Akazawa, 2011). Furthermore, Chaudhuri et al., (2019) found most Korean professional women, on a daily basis combating with the overwhelming glass ceiling philosophies that forces them to constantly re-evaluate their life choices of either pursuing a career path or raising a family.

For female academics who are mothers, it has become a herculean task trying to make it through daily work and family life during COVID-19, especially in Nigeria, which has a less egalitarian, collectivistic tradition (Mushiqur et al., 2018). With a population of almost 200 million spread across over 250 ethnic groups (Worldometrics, 2020), the Nigerian society is a sociocultural system that accepts high power distance (Hofstede, 1980), idealising expectations of unquestionable obedience and submission towards superiors (especially men) with acclaimed status and authority (Adisa et al., 2020). Furthermore, the existence of gender stereotypes and the marginalisation of female voices based on age-long glass-ceiling ideologies is a major hindrance to the career development and WLB of professional women (Akanji et al., 2019). Nash and Churchill (2020) have argued that the global pandemic has posed challenges to Australian female academics struggling with baby care and the homeschooling of their toddlers while simultaneously required to actively engage in research publication, online teaching, and other ancillary academic functions with the same tempo and rigour at home. These experiences can potentially lead to burnout, since personal resources (e.g. time, energy, and emotions) are strained in the process of juggling both work and family affairs. While much research has been undertaken on the WLB challenges confronting career women in western countries (Beham et al., 2012), similar studies in the African context remains in embryonic stages. Little is known from developing countries in Sub-Saharan Africa, such as Nigeria, where cultural orientations differ from more egalitarian, individualistic western cultures. 
Therefore, this article is a rudimentary effort to fill this gap in the literature, particularly in response to calls for context-specific studies focusing on Africa in order to extend knowledge and broaden our understanding of patriarchal proclivities and WLB issues facing Nigerian female academics working remotely and caring for their families during the COVID-19 pandemic. Focusing on the contemporary debates on stress, professional women, work, and family experiences during the period of the lockdown, specifically using the work-home resources (W-HR) theory as an explanatory model, this study hopes to answer, from a nonwestern perspective, the following question: How has the COVID-19 pandemic affected the work-life balance of mothers in academia who live in a patriarchal society?

In order to answer this research question, this article is structured as follows: a brief theoretical background on understanding WLB and the W-HR model is given. Thereafter, the methodology adopted for the data collection and analysis is presented, along with the study's findings and a discussion thereof. The article concludes by explaining the study's research and theoretical implications and proffered some recommendations. The study's limitations and areas for future research are also presented.

\section{Understanding Work-Life Balance and the Work-Home Resources Model}

The majority of academic research and policy debates on WLB has, in the main, focused on the imperative need for the working class (especially women) to improve the quality of their work-life aspirations and how employers might implement family-friendly policies to foster such achievement (Kelliher et al., 2018). More importantly, organisational interventions such as flexible work arrangements are proffered as incentives to engender work-life enrichment, facilitation, and positive integration (Haar, 2013). Greenhaus et al. (2003, p. 513) argued that achieving WLB is 'the extent to which an individual is equally engaged in - and equally satisfied with - his or her work role and family role'. Although WLB is widely assumed to be a matter of individual choice and circumstances, the realities of work-life intensity today are making employees strenuously try to juggle their work, family, and personal lives suitably (Morris et al., 2011). Stress and work-life conflicts are attendant consequences when this occurs. Often, work-life and occupational stress researchers have heavily relied on role theory (Kahn et al., 1964) to elucidate how role conflicts results in undesirable situations. Greenhaus and Beutell (1985) asserted that the struggles to attain a balance may result in a form of interrole conflict in which the role pressures from work and family domains are incompatible. Organisational research have predominantly focused on how employees must comply with standard working hours and appear physically at work which is always making adequate involvement in home affairs difficult (Eikhof et al., 2007; Ozbligin et al., 2011). This is because organisations now push for almost round-the-clock working hours resulting in role overload (MacDonald et al., 2013)

From this perspective, occupational stress and work-life scholars have given considerable attention to scrutinising work stressors (e.g. role ambiguity, role conflict, roles involving working long hours) - aspects of the work environment that can potentially harm the job attitude (e.g. work commitment) and overall life satisfaction of employees (Bowling et al., 2017). Given this context, however, we argue that role theory, regardless of its importance, has primarily adopted a restricted focus on office and workplace experiences, with limited attention given to recent development in the changing mode of employment locations and non-work spaces (Kelliher et al., 2018). This argument is particularly relevant during this 
period of the COVID-19 pandemic, which has blurred the work and non-work domains in a way that they never have been before, as millions of working adults have compulsorily transitioned to working from home in compliance with confinement policies (Corbera et al., 2020). Sinclair et al. (2020, p. 3) argued that harmonising work and family roles is now extremely problematic. This is because employee work roles commonly enacted at organisational locations at specific office hours (Monday-Friday) and family responsibilities expected to physically occur at home during evenings and weekends are fast disappearing as the pandemic is now making people to work from their kitchen tables, sitting rooms and other altered home-office spaces.

In re-evaluating WLB research, critics have argued that WLB often re-echoes narratives on how the nature of work times and environments are adversely affecting workers' personal and care needs at home (Özbilgin et al., 2010). This conception is, however, becoming irrelevant, especially during the COVID-19 pandemic as the world is grappling with the 'new normal' lifestyle - work has become home, and home has become work (Hochschild, 1997), with a heavy reliance on ICT. In order to keep WLB research more aligned with contemporary social trends before the pandemic, Grawitch and Barber (2010), using the conservation-of-resources (COR) framework, re-conceptualised WLB to focus on ways people try to manage diverse personal pursuits and expend their finite personal resources (e.g. time, money, emotions, and energy) in reconciling the increasing multiplicity of life's demands, whether the demand is required (e.g. work) or other preferred private life affairs. The COR, a prominent stress theory conceptualised by Hobfoll (1989), thus explains how people attempt to acquire, retain, and conserve resources - regardless of their environment. On the contrary, stress may occur and there may be a consequent risk of loss or an actual loss of such resources (Hobfoll, 2001). This is because people bring considerable number of resources into their daily lives and seek to achieve multiple gains, through the desire for resources to positively accumulate. However, people often experience repeated demands on these resources as they choose when, where, and how to allocate them due to their definable limits (Hobfoll, 2011). Despite the deep conceptual insights into the general loss-gain dynamics described by the COR theory, ten Brummehuis and Bakker (2012) provided a richer concept - the W-HR model - that builds on COR theory to explain the interplay between the demands and resources experienced in peoples' work and private life domains.

At the heart of the W-HR model lies the assumption that conflict becomes inevitable when contextual demands, either from a person's work or family, deplete the person's contextual and/or personal resources, which then results in diminished outcomes in either or both domains (ten Brummehuis and Bakker, 2012). The major highlights of the W-HR model are illustrated in Table 1 below.

\section{Insert Table 1 here}

From the constructs in the tabular content, contextual demands either from the work or family domain range from quantitative demands (i.e. overload) to cognitive demands with specific examples of each subtype. On the contrary, contextual resources (see subtypes) are conventionally located outside oneself and may be found within the social context of the individual to serve as buffers against the exacerbating effects of contextual demands (see examples). In addition, personal resources are those illustrated in the subtypes, with some examples therein. According to the W-HR model, these personal resources are often desirable 
and functional in achieving work goals and family demands. In sum, the adverse or enriching consequences of combining these dual roles have been demonstrated to lead to certain outcomes that are also exemplified in Table 1. ten Brummehuis and Bakker (2012) have further argued that macro resources identified with the context in which one lives, such as the cultural values, social equity and economic prosperity of a country can potentially influence the intensity of work-life conflict or enrichment that may likely occur. For instance, Mushfiqur et al. (2018) found that professional women (such as female medical doctors) experiencing excessive working hours, inflexible shifts, and the limiting conditions of gender role expectations - especially in developing countries such as Nigeria, Ghana, and Cameroun, where there are high unemployment rates and a pronounced culture of masculine hegemony often experience stressful outcomes as a result of the loss of personal resources (Table 1) due to the process of trying to integrate the work and family domains. A typical patriarchal society, such as Nigeria, tends to idealise a high power distance index, which is a cultural dimension that endorses an uneven distribution of power, authority, and status symbols among society members (Hofstede, 1980).

The history of patriarchy and its challenging impact on feminism is also dominant in some Asian countries, like Hong Kong, Qatar, Japan, Saudi Arabia, Lebanon, and China, where professional women - regardless of their knowledge-based economy careers, such as academia, medicine, ICT, and engineering - are culturally mandated to prioritise caregiving responsibilities (Abalkhail, 2017; Matsui et al., 2019). This phenomenon is found to be in conformity with the high power distance values that set the man (i.e. husband) as the head of the home, who holds absolute authority over women, children, and property in these nations (Salem and Yount, 2019). As a result of the COVID-19 pandemic lockdown, resource depletion (e.g. time and energy) may have affected working mothers more than fathers, as an extensive body of research has consistently portrayed women as primary caregivers who spend more time on familial responsibilities than work, regardless of their occupational demands (Shockley and Shen, 2016). These caregiving duties are more pronounced in developing countries, such as Nigeria, where employment relations are organised based on gender role norms (Adisa et al., 2019). While the depletion of psychological and physical resources (see Table 1) arising from tensions between both domains (which are competing for attention) appears universal, the cultural context plays an integral role in understanding the nature of the work-life imbalance confronting women. As discussed above, patriarchy is a value system that imposes male dominance over women and subjects them to all unpaid care duties. Therefore, patriarchal norms, which are prevalent in Africa and specifically Nigeria, have implications on the WLB of working mothers. To the best of the researchers' knowledge, there remains a paucity of research on the effects of patriarchy on the WLB of Nigerian female academics as the fear and threats of the COVID-19 pandemic soars. The aim of this article is to fill this research gap using the W-HR model as a theoretical framework to explain our findings.

\section{Methodology}

This study employs a qualitative method of enquiry, drawing on social constructionism, which epistemologically emphasises the discovery of rich contextual data obtained from people's lived experiences (Cresswell, 2013). This methodology was deemed appropriate because it provides a framework for developing an in-depth understanding of the research phenomenon under study and can lead to the discovery of taken-for-granted assumptions 
from detailed narratives (Easterby-Smith et al., 2012). Drawing on this naturalistic paradigm, telephone interviews were conducted with 28 female lecturers working in Nigerian universities. All participants preferred this method since majority claimed to enjoy using hands-free devices during conversation. Qualitative interviews are traditionally better when conducted on a face-to-face basis, which is often seen as necessary for strong rapport building and imperative for gathering rich qualitative data (Farooq and De Villiers, 2017). However, the lockdown policies enforced by the Nigerian government made it difficult to conduct one-to-one interviews. There are reported biases against telephone interviews, including the lack of ability to observe facial expressions, body language, and nonverbal cues, which are considered integral parts of the communication process during face-to-face interviews (Irvine et al., 2012). However, the researchers could discern that the telephone interview method made the participants feel relaxed and comfortable enough to disclose sensitive information with full knowledge that the lockdown policies required this conversation style. Moreover, the method allowed us to reach participants in a wider range of geographical locations (Novick, 2008). Nonetheless, all the participants were from commercial cities in the south-west region of Nigeria (Ogun, Oyo, Lagos, and Osun States) with a similar cultural heritage - they all identified with the Yoruba tribe. Their universities were also located in these metropolitan cities while the participants shared similar workfamily experiences during the pandemic based on the prevailing gender role differentials in Nigeria (Akanji et al., 2020).

Purposive sampling was undertaken due to the assumption that researchers of qualitative studies should have reasonable knowledge of the sample size to be used and should target the desired samples (Patton, 2015). Thus, key participants were solicited through the researchers' personal contacts and referrals, using a snowballing approach (Saunders et al., 2012). Furthermore, each participant's eligibility was based on the length of time they have worked with their current employers (a minimum of three years), their age (between 25 and 65 years old), and their marital status (married with dependent children). Other demographic features included the participants' religion, their university type, and their employment status (tenure track, i.e. full-time employment, or non-tenure track, a renewable yearly contract of employment). In order to fulfil our promise of confidentiality, pseudonyms were used to represent the interviewees, who were labelled 'Participant [number from 1-28]' for the purposes of this study (see Table 2).

\section{Insert Table 2 here}

Before the main interviews, pre-interview phone calls were held to briefly build rapport, create interest, and negotiate a convenient time for call-backs. Subsequently, each semistructured telephone interview lasted for 30-40 minutes. During dialogue with one of the researchers, who was solely responsible for the data collection process, the background noise of children crying, screaming, playing, and distracting their mothers was heard, which confirmed the challenges confronting female academics before we even questioned them. However, the participants were determined to forge ahead with the interviews, despite the disturbances. The interview style, based on open-ended questions, allowed for flexibility in the discussions and exploration of individual perceptions of patriarchy and WLB experiences during the pandemic. Representative of the questions asked are: 1. In your personal experience, what do you understand as 'work-life balance'? 2. Are you currently experiencing work-life balance as a female academic as the pandemic soars? 3. If you're not 
experiencing work-life balance, can you tell me why in more detail? 4. Could you please briefly share your experiences about the impact of patriarchy on your daily life, especially during this period of the COVID-19 lockdown? The entire telephone interviews were recorded, with the participants' consent. Notes were also taken during the process. After 23 interviews, it was felt that the 'saturation point' had been reached, because no further information was added that enhanced the findings of the study (Bowen, 2008). To confirm this position, five more interviews were undertaken, but they merely corroborated the existing themes.

\section{Data Analysis}

Following the completion of all material data collection, the digital recordings were electronically distributed to the researchers for thorough transcription. Thereafter, thematic analysis procedure (TAP) was applied in order to analyse the transcribed recordings. TAP is a qualitative design that is employed in research to identify, analyse, and report patterns (themes) within datasets (Braun and Clarke, 2006). At this stage, the researchers collectively started a meticulous data reduction process through open coding, which involved identifying key points in the transcribed interviews that are relevant to the research inquiry and thereby creating a word or phrase that significantly assigns a salient, summative, and essencecapturing feature that directly addresses our research question (Cresswell, 2013). Thereafter, cognate codes were identified and appropriately amalgamated to create conceptual categories, which made the first-order codes more compact and representational of similar underlying ideas. We did not impose codes a priori but rather remained open minded to emerging categories (Patton, 2015). Finally, the main categories were refined and further consolidated in a bid to generate theoretical explanations of the phenomenon under study. In so doing, we continued cross-comparisons of all material codes and intense interrogation of our conceptual categories during our debriefing sessions until we reached a compromise on what should constitute the main theoretical claims (i.e. themes) grounded in the data (Miles et al., 2014) concerning the impact of COVID-19 on the WLB of female academics living in a patriarchal society. In a nutshell, Table 3 highlights the main themes, number of responses as well as the approximated percentages of participants' responses falling under each theme.

\section{Insert Table 3 here}

The Table is further organised along the type of resources in the (W-HR) model drawn from data set and gives a more nuanced description of work-family conflict as a process whereby demands in one domain depletes personal resources and hinders satisfactory performance in the other domain (ten Brummehuis and Bakker, 2012).

\section{Findings and Discussion}

In more detail, an in-depth analysis of the main themes that emerged as responses to the research question are as follows:

\section{Career Stagnation}

There were strong beliefs among thirteen participants that the pervasive nature of the COVID-19 pandemic is making academic jobs more demanding in terms of the time and effort being dedicated to both remote working and care obligations happening simultaneously at home (see Table 13). Although all participants generally considered WLB as the ability to 
balance work with family commitments, many grumbled about how the curfews have resulted in reduced accomplishment of desirable work-related outcomes. Concerning how WLB is defined, the following quotations typify the participants' shared views:

For me, WLB means the ability to have sufficient time to meet my work demands as a lecturer and enough time for parenthood and leisure. However, mothering and at the same time working long hours from home has not been easy for me during the pandemic (Participant 1).

My understanding of WLB is the achievement of desirable involvement and commitment to my work as an academic as well as other private life matters, such as my role as a wife, mother, and carer to my husband's elderly mother (who is living with us) - but I'm struggling with working from home (Participant 2).

I think WLB is ensuring I gain some level of fulfilment from work as a senior lecturer aspiring to become a professor some day and to enjoy my family life as well, which is not only restricted to motherhood but also involves attending social functions, such as naming ceremonies, weddings, and other important family occasions. The fear of the coronavirus and movement restrictions are making my career and daily family routine very difficult (Participant 16).

The preceding excerpts suggest WLB means giving time, involvement, and satisfactory attention to work, parenting, leisure, and in-person socialisation. The findings underline the importance of family relations in Nigeria. In this context, a significant part of the social fabric of Nigeria is its collectivist culture, which emphasises the primacy of family institutions and communal living, firmly embedded in the country's collective identity (Ituma et al., 2011). Within the household setting, Nigerians (particularly women) develop social bonds by mandatorily growing a family support system, regardless of their career pursuits (Mordi et al. 2013). WLB is interpreted as embracing motherhood as a compulsory obligation that takes place within the confines of the home in conjunction with paid work. However, our study findings show women are struggling to balance motherhood and office work within a specific location (i.e. the home) due to the pandemic lockdown. Drawing on the (W-HR) model, it is evident from our findings that work-family conflict reflects a process that makes demands in one domain drain personal resources, amounting to diminished outcomes in the other domain (ten Brummehuis and Bakker, 2012) as a result of the pandemic. This drastic change has shaped the 'new normal' lifestyle, and this tells us about the difficulties facing women who are living and working simultaneously within a primary location that is predominantly meant for home affairs (Dillaway and Pare, 2008). The challenges confronting these professional women are further exacerbated by the Nigerian culture that is notorious for its extreme attitudes of well-defined domesticated expectations from mothers (Nwagbara, 2021). Despite the prevailing gender role expectations of homemaking, further evidence showed that about $45 \%$ of participants were unhappy with the unlimited hours devoted to academic work, which they claim is no longer commensurate with their salaries as a result of the COVID-19 crisis. Here, the thirteen participants defined their career success in terms of financial stability, with a particular interest in receiving a steady income and being seen as economically viable in supporting family needs.

I have been experiencing career and family difficulties since the spread of the deadly coronavirus, which is now hitting many Nigerian private universities hard due to the lockdown. For instance, we had no choice but to accept pay cuts, despite being mandated to continue lectures and teaching online at home. I'm stressed, lack motivation, and feel my career prospects are plummeting because being financially capable is the ideal in Nigeria. Making enough money from academia to cater for my family and having some to save for a rainy day is what I call success, but this is not the case today - despite working tirelessly from home during this global pandemic (Participant 4). 
WLB for me is problematic as the infectious virus is destroying lives and livelihood. After all the hard work and spending long hours teaching online, our efforts as lecturers aren't receiving the right credit. I now only get paid my basic salary because my university can't afford to pay other bonuses and allowances, which is a career decline for me. This is more strenuous than it was before the lockdown, because I'm also expected to supervise my children's classwork since we are all at home due to the lockdown. I'm no longer enjoying gainful employment and finding it challenging to financially support my immediate and extended families (Participant 11).

Central to the above statements is the monetary measurement of career success and the difficulty in achieving career success and financial prosperity during the COVID-19 lockdown. With a clear relevance to the W-HR framework, the desire for sufficient financial resources ranks as very important in Nigeria. The current findings are in line with those of prior studies (Ituma et al., 2011; Aluko et al., 2017) that have shown career-driven individuals in Nigeria prioritise wealth and gain admiration due to the ability to support their families financially. Nigerians are often willing to subject their career goals and aspirations to this sociocultural obligation. As such, a lack of capital resources is associated with career stagnation. From this perspective, financial resources (e.g. salaries, raises, and bonuses) are considered insufficient, and this results in stress. According to the (W-HR) model, capital resources adjudged as instrumental to facilitating performance is poor and a source of major concern from our findings.

Apart from the problems in achieving career success in terms of financial prosperity during the curfew (see Table 3), additional evidence from about $40 \%$ of the participants $(n=11)$ shows perceived negative career outcomes in other domains.

\begin{abstract}
My WLB is far from ideal. I experience mental chaos coming from anger and frustration at the way my publication track record is suffering because I'm overburdened with my children screaming, playing, and always disturbing me. I feel so tired and stressed every day. The COVID-19 lockdown is adversely affecting everything (Participant 19).
\end{abstract}

I am currently not enjoying a balance since the period of the compulsory lockdown. Unfortunately, I don't have any quiet space in my house that I can use as an office or a hiding place from my children. I literally carry my laptop with me everywhere in my house, with my four-year-old son always crying behind me for unnecessary attention. Given that my home is not conducive for work, I'm very worried about my career progression (promotion) this year (Participant 7).

The hardship imposed by the pandemic is making it hard to say I'm experiencing WLB, because the lockdown is sapping my positive energy, sense of accomplishment, and intrinsic satisfaction I derived from attending academic conferences, workshops, and being appointed as a visiting professor. I am not used to sitting down at home for this long. The sudden change in lifestyle due to the COVID-19 crisis is one of the most stressful periods of my life, but what can I - or anyone - do? (Participant 14).

As a result of the COVID-19 lockdown, the participants in this category expressed anger, frustration, worry, and emotional stress as a result of the struggles they have been experiencing due to their lack of ability to meaningfully engage with academic research; the unsuitability of their home for work; and their inability to attend academic conferences, workshops, and other career advancement agendas in person. Conceptually, these responses highlight how the COVID-19 lockdown has threatened, taxed, and/or exceeded personal resources contextualised as psychological conditions (positive emotions), career advancement (producing research publications), quality of life (work-life balance), physical environment (a good home office space), and personal characteristics (achieving personal career fulfilment). Therefore, it would seem reasonable to assume that the primacy of the foregoing resource losses, without the prospect of gaining them while the pandemic persists, confirms that it is 
psychologically harmful for these women to lose resources as contextual demands, referring to the physical, emotional and social contexts of working from home is having a profound negative impact on career prospects (Halbesleben et al., 2014).

Following the unpleasant effects of COVID-19 on the world of work, our findings further suggest the depletion of energy perceived as insufficient physical, mental, and emotional resources for responding to childcare pressures (e.g. 'I'm overburdened with my children screaming, playing, and always disturbing me') as well as academic work demands arising almost simultaneously. Drawing on the W-HR model, people are presumably motivated to spend energy on personal pursuits they find meaningful and rewarding (Grawitch et al., 2010). However, the confinement policies forcing a compulsory switch to working from home is claiming to adversely affect career success conceptualised in terms of personal fulfilment derived from finding satisfaction and excitement when participating in scholarly activities, as illustrated in one of the sampled excerpts ('...the lockdown is sapping my positive energy, sense of accomplishment, and intrinsic satisfaction...'). Furthermore, literature on work-family conflict spillover (Sok et al., 2014; 2010; Du et al., 2018) suggests that some experiences occurring in one domain can be carried into the other (whether it is work-to-home negative spillover or the reverse). This argument is particularly relevant as boundaries between work and family affairs are becoming increasingly blurred due to the COVID-19 lockdown. Given the finite nature of resources (mood, feelings, and energy, for example), the repeated demands in one sphere drain the availability of these resources and thereby limit what is left for optimal functioning in other domains, which is evident in the concerns raised by some participants.

\section{Health Concerns}

About seventeen of the participants were specifically concerned with how the COVID-19 pandemic has taken a toll on their physical wellbeing, with claims of inability to find respite, even in the solace of their homes. Approximately 60 percent of the participants (see Table 3) were of the view that WLB is achievable when they are in good health, but the pandemic has made it difficult to adequately deal with health-related issues. Two of the participants commented as follows:

\footnotetext{
WLB is feasible when a person is healthy [...] but for me, it has been a tough experience, because the pandemic forced everyone to stay at home and do less in terms of social interactions and exercise. This is really affecting my health. I have been diagnosed with high blood pressure, and this has been made worse by my lack of physical activity during this period of lockdown, which is coupled with intense family and academic responsibilities. More agonising is my pay cut, which is making it very difficult for me to purchase medications on regular basis (Participant 13).

No, I'm not enjoying WLB, as COVID-19 continues to escalate at an unprecedented scale. As an academic, I'm not physically active, I have a lot of screen time, irregular sleep patterns because of my children, and a poor diet, which has resulted in weight gain. Moreover, sitting for long hours on my laptop has caused me backache and a stiff neck [...] The financial strain I am currently enduring as a result of my slashed salary is another problem (Participant 22).
}

The expressions above illustrate how the unexpected shift to remote working and the prolonged effects of the lockdown are having negative health outcomes on professional working mothers. In addition, our findings resonate with those of prior studies (Wajeman et al., 2009; Mordi et al., 2013) that suggest that WLB is sometimes defined in terms of health concerns. For instance, Poms et al. (2016) argued that poor WLB has been shown to have an 
adverse effect on the cardiovascular and mental health of women. Similarly, our study reveals the disruptions due to the COVID-19 lockdown made women struggle with health-related stressors impeding their career, family life, and personal finances. Drawing on W-HR model that is built on the conservation of resource theory, it is suggested that people usually benefit psychologically and recover faster when they feel that they are financially capable of meeting certain life demands, such as health challenges (Hobfoll, 2011).

However, the emerging findings on the impact of COVID-19 highlight how the pandemic is not only compromising the work-life integration and physical wellbeing of female academics, but they also indicate concerns about jobs being disproportionately affected by pay cuts, which leaves them with insufficient financial resources to attend to their personal healthcare needs. According to Grawitch et al. (2010), lack of financial resources has been associated with stress, anxiety, and decreased life satisfaction, because working adults are normally motivated to retain or enhance economic resources in a bid to potentially boost their capabilities in solving life problems or cope with difficult realities as the need arises.

Since women have taken on greater care demands at home with being active dual earners, it is possible to project that the effects of the COVID-19 will result in a prolonged dip in women's incomes (Nash and Churchill, 2020). Such impacts risk rolling back the already fragile economic gains made in female labour force participation, limiting women's ability to support themselves and their families as the pandemic persists (Nicola et al., 2020). In pursuing strategies aimed at mitigating financial hardships arising from slashed income, further evidence from the study revealed these women claim to re-adjust their monthly budgets, cutting back on discretionary spending (non-essential expenses) and temporarily stopping their retirement contributions (pension scheme) in order to free up more cash needed to meet family demands. For example, expressions such as 'the salary cuts made me seriously downsize my monthly shopping list for the family'; '...in coping with the difficult financial hardships as a result of income cuts, I only buy want I need and no longer what I want'; 'I had to suspend my monthly pension funds to free up some cash for me to spend' underpin some plan of actions aimed at attenuating financial losses. Drawing on the W-HR model (which is built on the COR theory), our findings here justify the propositions that people attempt to retain and protect personal resources (e.g. finances) by demonstrating coping behaviours targeted at mitigating demanding situations appraised as stressors causing conflicts between the work and family domains (Hobfoll, 2011).

\section{Male Chauvinism}

An overwhelming percentage of the interviewed female academics (see Table 3) admitted experiencing a high level of role overload and caregiving strain during the lockdown, specifically due to the patriarchal nature of Nigerian society, where a system of social and gender stratification empowers men to dominate women in almost every sphere of life (Adisa et al., 2019). This supports previous studies (Mordi et al., 2013) that found that Nigerian women are viewed as traditional homemakers and are expected to deploy a considerably higher level of emotional resources (affection, love, and empathy) to their care responsibilities than men, who are considered as the absolute heads of their homes. Since all the participants (reached by phone) were drawn from a particular region of Nigeria (the south-west region of the country) - Ogun, Oyo, Lagos, and Osun States - they all gave similar accounts of the extent to which patriarchal values adversely affected their WLB, 
especially where Yoruba women, as an ingrained tradition, are expected to respect and comply to their husbands' dictates relating to family affairs (Staveren and Odebode, 2007). As such, it was found that this patriarchal cultural expectation of prioritizing family needs over work made resources such as time and physical energy of these women volatile (ten Brummehuis and Bakker, 2012). According to the W-HR model, it means that once these transient resources are utilized on familial matters, it becomes difficult to allocate similar resources to meet occupational demands.

Furthermore, very few of the participants acknowledged that patriarchal ideologies are more severe in rural areas, particularly in some northern parts of Nigeria. Rural women are said to be highly discriminated against in terms of employment opportunities; access to social support; education; health status; religious background; family decisions; and much more (Aderinto, 2017). Illustrative quotes that align with these findings are as follows:

Since some of our husbands, particularly from the south-west of Nigeria, value education - unlike some other parts of Nigeria - we see a higher number of female academics from this part of the country. However, the COVID lockdown is making our WLB problematic, because we are at home with our husbands - a typical Yoruba woman is expected to respect the authority of the man (Participant 23).

Masculine supremacy is so much embedded in our society, but harsher in rural (e.g. a few northern) areas of the country, where female illiteracy is very high. Despite being educated, we are still mandated to prioritise home affairs (Participant 24).

Our findings also indicate that these women, who are full-time academics, work to support the family purse. However, the 'male breadwinner' ideology implies that the men still hold authority over women in terms of finances. Based on this societal perception and internalised assumptions of masculine supremacy, concerns were raised by participants about the lack of spousal support in helping with family care during the period of the lockdown, which exacerbates WLB difficulties and stress:

The dominance of patriarchal norms in our society is frustrating and stressful. My husband believes that the attributes of a good wife are to carry the entire burden of cooking family meals, childcare, and washing and cleaning the home - while the man is the financer of the home. During this lockdown, I have been working almost around the clock as a mother - at the expense of my academic work. I have to stay up late at night to record my class lessons for my students to watch online when my two-yearold is asleep, and I doze off sometimes on the couch. Although having children in Nigeria is priceless, and I draw strength from always having them around me, I still feel so exhausted keeping up especially now that everything happens at home, and with little or no help from my husband (Participant 15).

One exasperating experience for me is our societal ideology that women, regardless of their status and profession, should be solely responsible for household chores and children needs, while our men (husbands) hold authority over us. The extremity of the lockdown is making it difficult for me and my husband to negotiate our work schedules appropriately. He always demands his schedules should be prioritised as head of the home. Women are always subservient [...], exposing us to time squeeze and work-family conflict (Participant 10).

Ordinarily, it appears Nigerian universities traditionally organise the academic career path to fit male life patterns, which is making it more problematic for women to advance their careers. The period of the lockdown has worsened the situation for me, because my husband - who is also an academic believes that I should always focus on family matters than work [...] The institutional and social nature of patriarchy makes it difficult to allocate time appropriately (Participant 5).

The perspectives of the participants demonstrate how patriarchal proclivities embedded in Nigeria's cultural and institutional structure undervalue the WLB of professional women. 
They particularly cited the propagation of male chauvinism during the pandemic as exacerbating time-based conflicts. For instance, evidence of time-based conflict emerging from the propensities of masculine hegemony is making time devoted to the home front difficult to perform occupational demands (e.g. 'During this lockdown, I have been working almost around the clock as a mother at the expense of my academic work'). In this context, patriarchy represents a significant hindrance to the amount of time spent working from home. Although time with family is viewed as a valuable resource (e.g. 'Although having children in Nigeria is priceless, and I draw strength from always having them around me...'), this is mainly driven by patriarchal expectations, which results in exhaustion and stress. This occurs due to the inability to adequately allocate time to meet career obligations following the investment thereof in family matters, with 'little or no help from my husband' (expressed by Participant 15). This is because domestic duties in Nigeria are allocated according to a person's gender. Our findings on patriarchy are generalizable to some other male-dominated cultures, such as countries like India, Indonesia, and Iran) and Palestinian territories (e.g. Gaza), which have been connected with strong male domination as a result of the high power distance orientation found in those parts of the world (Haj-Yahia, 2005). Generally, gender inequality, sexism, and masculine superiority, inter alia, are characteristics of these societies, where culture and religion have exclusively imposed caregiving responsibilities on women, regardless of their white-collar professions (Sultana, 2011). This gender stereotypical features are similar to the cultural and gender dynamics that exist in Nigeria.

Indeed, during the COVID-19 pandemic, it evident that resources (e.g. time and energy) are often hard to acquire and maintain desirably, and resource loss according to the W-HR model is considered to be more salient and of greater impact than resource gain (Halbesleben et al., 2014). Nash and Churchill (2020) argued that, even at the best of times, female academics with care responsibilities rarely enjoy the luxury of being overwhelmed with career focus but are rather immersed in domestic tasks - more so than men. Reflecting on some participants' views, it is expected for women to work outside of the home. They are still perceived as housewives, while their husbands are meant to be superior earners. Mushfiqur et al. (2018) highlighted that this situation is embedded in management ethos and organisational culture, which prioritises the economic resources and financial prowess of men at the expense of women's WLB needs. Thus, prior studies have found that extreme patriarchy breeds gender stereotyping, which is more severe in South Asia and Africa than it is in western countries (Adya, 2008). For instance, gender equality has been a well-established priority of EU member nations. Significantly, gender equality is known to be an integral feature of EU sustainability objectives and strategy through the implementation of policies on gender mainstreaming (Grosser, 2009).

More specifically, EU defines gender equality as 'an equal visibility, empowerment and participation of both sexes in all spheres of public and private life... [this] is not synonymous with sameness, with establishing men, their lifestyle and conditions as the norm ... [this] means accepting and valuing equally the differences between women and men and the diverse roles they play in society' (Council of Europe, 1998, pp. 7-8). Therefore, the deeper and more resilient aspects of social structure in western contexts conform to the right to live without gender discrimination, which is perpetuated in Nigeria by patriarchy deeply ingrained in its society.

\section{Conclusion}


In summary, this study has provided qualitative evidence on the impact of COVID-19 on Nigerian female academics working remotely and negotiating caring responsibilities within a patriarchal context. Overall, our findings suggest that academic women with children are facing significant challenges in combining work demands with childcare. Situated in a national context (Nigeria) that has been neglected in favour of extensive media reports on the negative impact of the pandemic in western regions, the present study has focused on the consequences of the COVID-19 crisis on the WLB of academic mothers living in an inegalitarian society. Thus, the current pandemic has affected, in unique gender-specific ways, their traditional status as caregivers and home managers (Akanji et al., 2020). Our findings have unveiled how the COVID-19 lockdown has intensified the workload of Nigerian mothers/academics and has thus caused profound role conflicts and health problems, which have further been exacerbated by the ingrained sociocultural pressures of patriarchy and high power distance values. As such, our study has made important research and theoretical contributions.

\section{Research and Theoretical Implications}

In terms of research implications, our findings show that the definition of WLB by female academics generally conforms to existing conceptualisations that perceive WLB, in its broadest sense, to mean a satisfactory level of involvement in and devoting adequate time to paid work, family, and other personal social matters (MacDonald et al., 2013). Our data points to a wide range of activities that are seen to comprise non-work domains, including caring for the elderly, leisure, socialisation, and creating time to deal for health matters apart from the well-established devotion to childcare responsibilities. Accordingly, these findings adopt a more inclusive conception of the non-work domain to broadly include diverse life demands - whether preferred or required - to which people often deploy a reasonable level of resources (e.g. time, effort, and money) to achieve, subject to situational or cultural dictates (Kelliher et al., 2018). As such, we build on earlier critiques by scholars who argue for greater inclusivity of multiple activities of life in non-work categorisations despite that the original focus of WLB research emerged from an increase of female participation in the labour market and the struggles working mothers encounter in combining work and childcare (Ozbilgin et al., 2011).

Given the far-reaching and devastating impact of COVID-19 on lives and livelihood around the world, the study participants have highlighted critical challenges in their ability to manage their WLB due to the lockdown, with profound adverse effects on their contextual and physical resources (e.g. career and health) respectively (ten Brummehuis and Bakker, 2012), while broader cultural inclinations of patriarchy (i.e. macro resource) underscore issues of feminine subordination - exacerbating stress. More specifically, our findings provided valuable insights into the specificities and contextual meaning attached to career success in Nigeria. Our findings adds to the discourse on work-family balance challenges by substantiating the foregoing evidence that work-family disharmony is dependent on the incompatibility of contextual demands with the amount of contextual and personal resources (see Table 1) that is the root cause of inter-role conflict. For instance, our data demonstrates that the economic stressors arising from reduced earnings (i.e. money as personal resource) as well as other negative career outcomes, is increasing difficulties for female academics to reconcile work and family demands during the lockdown. Additionally, patriarchy as a social system in Nigeria highlights an extreme gender-based division of labour, which is a huge 
obstacle that precludes professional women from achieving satisfactory WLB. This is because a considerable number of personal resources (e.g. time, emotions, and finances) are expected to be deployed to home and childcare management, even at the expense of career pursuits. Therefore, work-life research needs to capture and address the effects of this wider macro-context resource specificity (patriarchal propensities) challenging the WLB of professional women and the counterproductive outcomes on work behaviours, especially during the COVID-19 pandemic, when millions of workers transitioned into working from home (Sinclair et al., 2020).

Concerning the study's theoretical implications, our findings highlight how the W-HR model is integral to understanding WLB with an emphasis on the work-family imbalance and stress confronting working mothers during the COVID-19 pandemic. As such, it is argued that these negative experiences are triggering backlash attitudes that may be detrimental to their universities and career outcomes in the form of demotivation, lack of commitment, stress, and low morale. Through the lens of the W-HR framework, we have shown how the debilitating effects of the COVID-19 crisis have necessitated families to self-isolate at home, thereby straining the personal resource allocation (e.g. time, energy, emotions, and finances) of female academics as they face daily struggles in combining parenthood with career goals in a national context that is highly patriarchal. With all of these factors in mind, our findings may refocus the discourse on WLB, which often highlights the need for office flexibility to mitigate role conflict experiences, to how COVID-19 has brought unprecedented disruption to how people (particularly working mothers) are able to allocate their time and energy in ways that can optimally align with their preferences - as work and non-work domains are becoming increasingly blurred during the pandemic (Nash and Churchill, 2020).

Drawing on W-HR theory, personal resources are potentially valuable to the extent to which they are perceived to help a person achieve their definite goals and life aspirations (Halbesleben et al., 2014). However, the COVID-19 pandemic has made WLB during the lockdown worse for female academics in terms of their ability to conserve and maintain personal resources, since working in the exceptional conditions caused by the pandemic has been found to be increasingly stressful and damaging to their careers. In addition, resource drain has made female academics face increased threats to their health as restrictions on movement and economic losses due to pay cuts have compromised their wellbeing. Furthermore, the prevalence of patriarchy has shaped women's behaviour in ways that undermine the amount of time they have to respond to career and caregiving demands. This differential gender role socialisation norm adversely affects the time management of female academics, who are constantly subject to men's (self-perceived) superior status quo (Adisa et al., 2019). Accordingly, a primacy afforded in Nigerian culture to the family and the associated normative expectations that women are responsible for more unpaid care work than men contribute to time biases - it is always expected that women's non-work time should mainly focus on domestic affairs, to be routinely invaded by male chauvinism.

\section{Recommendations}

From the personal accounts of our study, it is evident that the career decline, health problems, and family challenges brought on by COVID-19 for female academics living in a maledominated society are key problems that cannot be ignored. Therefore, practical recommendations, such as the implementation of institutional family-friendly support 
systems addressing patriarchal perplexities can help mitigate resource drain and address the negative narratives emerging from the study. Institutional and cultural dynamics propelling WLB practices that are favourable to working mothers are weak in Nigeria due to the society's strong emphasis on patriarchal values. This necessitates an urgent need for university management teams to implement regulatory and supervisory structures as well as family-friendly policies (e.g. greater work flexibility at home) that can provide considerable support for the population under study (i.e. female academics) and their families during this crisis. It is recommended that the Nigerian universities in this study can deploy and/or attach teaching and graduate assistants to assist female academics struggling with mothering responsibilities whilst working from home. Thus, reducing the workload which can potentially ease working hours, without any backlash effect on the career prospects of these working mothers, could be a way out. Overall, it is difficult to find any published information of what Nigerian universities are currently doing to help, in terms of policy and WLB support for female academics during this period of the pandemic. Using the universities of our present study as case studies, we therefore recommend that Nigerian universities should begin to engage in supportive WLB measures such as allowing compressed working hours, job sharing, rotational shifts, provision of free virtual learning platforms and necessary palliatives as buffers against the hardships that academic women with parenting roles are enduring as a result of the COVID-19 crisis.

In further addressing the considerable difficulties confronting women in reconciling work and family affairs as a result of the pandemic, universities could educate academics with parenting responsibilities that, for work-family needs to translate into supportive policies, a sense of entitlement has to be developed (Santos and Cabral-Cardoso, 2008). This is to say, mothers in academia are allowed to voice their needs and are entitled to negotiate more flexible work hours and arrangements given the patriarchal nature of the Nigerian society. Perceiving this as a global issue, Nash and Churchill (2020) rightly noted (in a western context) how female academics with childcare responsibilities are facing significant challenges in balancing their career and caregiving demands during the pandemic, with evidence of little or no support from their universities.

Therefore, Nigerian universities should identify the most pressing needs of employees (particularly female academics) and their families by carrying out meaningful and contextually relevant social dialogue that will refocus staff's attention on how working from home can bring multiple and substantial benefits that can enhance positive work-family balance. Better online communication through institutional websites on the importance of discussing WLB difficulties with a superior or line manager or taking a period of leave can help alleviate some of the challenges confronting female academics struggling with caring roles whilst working remotely during the pandemic. In addition, research that captures positive individual experiences can be utilised to inform pertinent questions on how working mothers in academia are possibly managing and/or negotiating work and family affairs during this time of crisis (Sinclair et al., 2020). Results therein can be used in WLB policy formation that are relevant to situations of many Nigerian female academics especially where it remains a deep-seated idea in the Nigerian culture and social policy that women are primary caregivers. Evidently, patriarchy has set the parameters for women's inequalities and workfamily challenges, which invariably affect social sustainability outcomes for Nigerian working mothers. Thus, it is also imperative for feminist citizenship discourse and advocates 
of gender equality in Nigeria to focus on the need to incorporate 'ethics of care and social justice' agendas for working women, who shoulder the greater part of the home's domestic responsibilities (Lister, 2003).

\section{Limitations and Directions for Future Research}

While this article has advanced knowledge about the challenges facing women academics during the COVID-19 lockdown in a non-western context, it does have some limitations, which in turn open up opportunities for future research. Firstly, our qualitative findings are based on only a small sample size (28 interviews), which makes it challenging to generalise the results to other non-western contexts, like, for example, other countries in the African continent. Despite the importance of qualitative analysis, which helps to interpret peoples' perspectives on social reality most accurately, future research could engage statistical approaches to test a larger representative sample for more generalisation purposes (Saunders et al., 2012). Secondly, the present study is based on the sole accounts of the WLB difficulties confronting professional mothers, which makes our findings subjective and may portray tendencies for participants to answer in ways that make social desirability biases plausible (Fisher, 1993). Since the COVID-19 lockdown has affected everyone, we hope our study opens up new research opportunities that explore male academics, who are fathers and were also negatively affected by the pandemic lockdown. It would be exciting to report views from the perspective of men, who are rarely considered in global WLB debates. Finally, it would be interesting to engage in cross-cultural research that compares the impact of the pandemic in Nigeria with that in the western context, as we navigate different cultural perspectives to work-life research as the world grapples with the unprecedented COVID-19 crisis.

\section{References}

Abalkhail, J. M. (2017) 'Women and leadership: challenges and opportunities in Saudi higher education', Career Development International, vol. 22, no. 2, pp. 165-183.

Adisa, T. A. Abdulraheem, I., and Isaika, S. B. (2019) 'Patriarchal hegemony: Investigating the impact of patriarchy on women's work-life balance', Gender in Management: An International Journal, vol. 34, no. 1, pp. 19-33.

Aderinto, A. A. (2017) 'Patriarchy and culture: The position of women in a rural Yoruba community, Nigeria', The Anthropologist, vol. 3, no. 4, pp. 225-230.

Adisa, T. A., Oruh, E. S., and Akanji, B. (2020), 'A critical discourse analysis of the link between professional culture and organisational culture', Employee Relations, vol. 42, no. 3, pp. 698-715.

Akanji, B., Mordi, C., and Ajonbadi, H. (2020) 'The Experiences of Work-Life Balance, Stress, and Coping Lifestyles of Female Professionals: Insights from a Developing Country', Employee Relations: An International Journal, vol. 42, no. 4, pp. 999-1015.

Akanji, B., Mordi, M., Ituma, A., Adisa, T., and Ajonbadi, H. (2019) 'The Influence of Organisational Culture on Leadership Style in Higher Education Institutions', Personnel Review, vol. 49, no. 3, pp. 709-732. 
Akazawa, J. (2011), "The current situation and future challenges for research on sexuality in Japanese heterosexual couples", Feminism \& Psychology, Vol. 21 No. 4, pp. 522-528.

Aluko, Y., Adewusi, A., and Kalejaiye, P. (2017) 'Career Progression and Satisfaction among Female Academics of Selected Universities in Southwest, Nigeria', The Nigerian Journal of Sociology and Anthropology, vol. 15, no. 2, pp. 63-86.

Bao, W. (2020) 'COVID-19 and online teaching in higher education: A case study of Peking University’, Human Behaviour \& Emerging Technologies, Wiley, Vol. 2, pp. 113-115.

Bowen, G. A. (2008) 'Naturalistic inquiry and the saturation concept: A research note', Qualitative Research, Sage Publications, vol. 8, no. 1, pp. 137-152.

Bowling, N. A., Khazon, S., Alarcon, G. M., Blackmore, C. E., Bragg, C. B., Hoept, M. R., Barelka, A., Kennedy, K., Wang, Q., and Haiyan, L. (2017) 'Building better measures of role ambiguity and role conflict: The validation of new role stressor scales', Work \& Stress, vol. 31, no. 1, pp. 1-23.

Braun, V. and Clarke, V. (2006), 'Using thematic analysis in psychology', Qualitative Research in Psychology, vol. 3, no. 2, pp. 77-101.

Chen, Y. and Li, L. (2020) 'SARS-CoV-2: Virus dynamics and host response', The Lancet: Infectious Diseases, Vol. 20 No. 5, pp. 515-520.

Council of Europe (1998). Gender mainstreaming: Conceptual Framework. Methodology and Presentation of Good Practice, Strasbourg, Council of Europe.

Corbera, E., Anguelovski, J. H., and Ruiz-Mallén, I. (2020) 'Academia in the Time of COVID-19: Towards an ethics of care', Planning Theory \& Practice, Taylor \& Francis [Online]. Available at: https://doi.org/10.1080/14649357.2020.1757891 (Accessed 11 June 2020).

Creswell, J. W. (2013). Research design: Qualitative, quantitative, and mixed methods approaches. Sage Publications.

Dillaway, H. and Pare, E. (2008) 'How cultural debates about stay-at-home versus working mothers define women and home', Journal of Family Issues, vol. 29, no. 4, pp. 437-464.

Du, D., Derks, D., and Bakker, A. B. (2018) 'Daily spillovers from family to work: A test of the work-home resource model', Journal of Occupational Health Psychology, vol. 23, no. 2, pp. 227-247.

Easterby-Smith, M., Thorpe, R., and Jackson, P. (2012) Management Research, 4th ed., London, Sage Publications.

Eikhof, D. R., Warhurst, C., and Haunschild, A. (2007), 'What work? What life? What balance?' Employment Relations, vol. 29, no. 4, pp. 325-333.

Elliot, L. (2020), 'Prepare for the coronavirus global recession.' The Guardian [Online]. Available at https:/www.theguardian.com/business/2020/mar/15/prepare-for-thecoronavirusglobal-recession (Accessed 11 June 2020). 
Farooq, M. B. and De Villiers, C. (2017) 'Telephonic qualitative research interviews: When to consider them and how to do them', Meditari Accountancy Research, vol. 25, no. 2, pp. 291-316.

Fisher, R. J. (1993), “Socail desirability bais and the validity of indirect questioning” Journal of Consumer Research, Vol. 20 No. 2, pp. 303-315.

Grandey, A. A. and Cropanzano, A. (1999) 'The conservation of resources model applied to work-family conflict and strain', Journal of Vocational Behaviour, vol. 54, no. 9, pp. 350370 .

Grawitch, M. J., Barber, L. K., and Justice, L. (2010) 'Rethinking the work-life interface: It's not about balance, it's about resource allocation', Applied Psychology, Health and WellBeing, vol. 2, no. 2, pp. 127-159.

Greenhaus, J., Collins, K. M., and Shaw, J. D. (2003) 'The relation between work-family balance and quality of life', Journal of Vocational Behaviour, vol. 63, no. 3, pp. 510-531.

Halbesleben, J. R. B., Neveu, J. Paustian, S. C., and Westman, M. (2014) 'Getting to the 'COR': Understanding the role of resources in conservation of resources theory', Journal of Management, vol. 40 no. 5, pp. 1-31.

Haar, J. M. (2013) 'Testing a new measure of WLB: A study of parent and non-parent employees from New Zealand', The International Journal of Human Resource Management, vol. 24, no. 17 , pp. 3305-3324.

Haj-Yahia, M. M. (2005) 'Can people's patriarchal ideology predict their beliefs about wife abuse? The case of Jordanian men', Journal of Community Psychology, vol. 33, no. 5, pp. $545-567$.

Hochschild, R. A. (1997). The time bind: When work becomes home and home becomes work. New York, Metropolitan Books.

Hobfoll, S. E. (1989) 'Conservation of resources: A new attempt at conceptualizing stress' American Psychologist, vol. 44, pp. 513-524.

Hobfoll, S. E. (2011), 'Conservation of resources theory: Its implication for stress, health, and resilience', In S. Folkman (Ed.), The Oxford Handbook of Stress, Health, and Coping, Oxford, Oxford University Press, pp. 127-147.

Hobfoll, S. E. (2001), 'Conservation of resources: A rejoinder to the commentaries', Applied Psychology: An International Review, vol. 50, pp. 419-421.

Hofstede, G. H. (1980) Cultures' consequences: International differences in work-related values, Beverly Hills, CA, Sage Publications.

Ituma, A., Simpson, R., Ovadje, F., Cornelius, N., and Mordi, C. (2011), 'Four domains of career success: How managers in Nigeria evaluate career outcomes', The International Journal of Human Resource Management, vol. 22, no. 17, pp. 3638-3660.

John Hopkins University Coronavirus Resource Center. [Online]. Available at https://coronavirus.jhu.edu/map.html (Accessed 10 June 2020). 
Kahn, R. L., Wolfe, D. M., Quinn, R. P., Snoek, J. D., and Rosenthal, R. A. (1964) Organisational stress: Studies on role conflict and ambiguity. Oxford, Wiley.

Kelliher, C., Richardson, J., and Boiarintseva, G. (2018) 'All work, all life? Reconceptualising work-life balance for the 21st century', Human Resource Management Journal, vol. 29, no. 1, pp. 97-112.

Lister, R. (2003) Citizenship: Feminist perspective (2nd ed.) London, Palgrave.

Matsui, T., Sato, M., Kato, Y., and Nishigori, H. (2019) 'Professional identity formation of female doctors in Japan - gap between the married and unmarried', BioMed Central (BMC) Medical Education, vol. 19, no. 55, pp. 1-9.

McDonald, P., Townsend, K., and Wharton, A. (2013), 'The legitimation and reproduction of discourse-practice gaps in work-life balance', Personnel Review, vol. 42 no. 2, pp. 205-222.

Miles, M. B., Huberman, A. M., and Saldana, J. (2014). Qualitative data analysis: A method sourcebook (3rd ed.). New York: Sage Publications.

Mordi, C., Mmieh, F., and Ojo, S. I. (2013) 'An exploratory study of managers, perspective of work-life balance in Nigeria: A case analysis of the Nigerian banking sector', Thunderbird International Review, vol. 55, no. 1, pp. 55-75.

Morris, L. M., Heames, T. J., and McMillan, H. S. (2011), 'Human resource executives' perceptions and measurement of the strategic impact of work/life initiatives', Human Resource Development Quarterly, vol. 22, no. 3, pp. 265-295.

Mushfiqur, R., Mordi, C., Oruh, E. S., Nwagbara, U., Mordi, T., and Turner, I. M. (2018) 'The impacts of work-life-balance (WLB) challenges on social sustainability: The experience of Nigerian female medical doctors', Employee Relations, vol. 40, no. 5, pp. 868-888.

Nash, M. and Churchill, B. (2020) 'Caring during COVID-19: A gendered analysis of Australian university responses to managing remote working and caring responsibilities', Gender, Work \& Organisation, pp. 1-14 [Online]. Available at https://doi.org/10.1111/gwao (Accessed 10 June 2020).

Nicola, M., Alsafi, Z., Sohrabi, C., Kerwan, A., Al-Jabir, A., Losifidis, C. Agha, M., and Agha, R. (2020) 'The socio-economic implications of the coronavirus pandemic (COVID19): A review’, International Journal of Surgery, vol. 78, no. 1, pp. 185-193.

Novick, G. (2008) 'Is there a bias against telephone interviews in qualitative research?', Research in Nursing \& Health, vol. 31, no. 4, pp. 391-398.

Nwagbara, U. (2021) 'Institutionalised patriarchy and work-life balance (WLB) challenges for female medical doctors: The case of Nigeria', Equality, Diversity and Inclusion, vol. 40, no. 3 , pp. $355-369$.

Ozbilgin, M. T., Beauregard, T. A., Tatli, A., and Bell, M. P. (2011) 'Work-life, diversity and intersectionality: A critical review and research agenda', International Journal of Human Resource Management, vol. 13, no. 2, pp. 177-198.

Patton, M. Q. (2015), Qualitative research and evaluation methods: Integrating theory and practice (4th ed.). Los Angeles, Sage Publications. 
Poms, L.W., Fleming, L. C. and Jacobsen, K. H. (2016), "Work-family conflict, stress, and physical and mental health: A model for understanding barriers to and opportunities for women's well-being at home and in the workplace", World Medical \& Health Policy, Vol. 8 Issue 4, pp. 444-457.

Salem, R. and Yount, K. M. (2019) 'Structural accommodations of patriarchy: Women and workplace gender segregation in Qatar', Gender, Work \& Organization, vol. 26, no. 4, pp. 501-519.

Santos, G. G. and Cabral-Cardoso, C. (2008) 'Work-family culture in academia: A gendered view of work-family conflict and coping strategies', Gender in Management, vol. 23, no. 6, pp. $442-457$.

Saunders, M., Lewis, P., and Thornhill, A. (2012), Research methods for business students (6th ed.). London, Prentice Education Limited.

Sinclair, R. R., Allen, T., Barber, L., Bergman, M., Britt, T., Butler, A., Ford, M., Hammer, L., Kath, L., Probst, T., and Yuan, Z. (2020), 'Occupational health science in the time of COVID-19: Now more than ever', Occupational Health Science, Springer [Online]. Available at https://doi.org/10.1007/s4152-020-00064-3 (Accessed 4 June 2020).

Shockley, K. M. and Shen, W. (2016) 'Couple dynamics: Division of labour', In T. Allen \& L. Eby (Eds.), Oxford Handbook of Work and Family. Oxford, Oxford University Press.

Staveren, I. and Odebode, O. (2007), "Gender norms as asymmetric institutions: A case study of Yoruba women in Nigeria”, Vol. 41 No. 4, pp. 903-925.

Ten Brummelhuis, L. L. and Bakker, A. B. (2012) 'A resource perspective on the work-home interface: The work-home resources model', American Psychologist

World Health Organization, Coronavirus disease (COVID-19) Pandemic [Online]. Available at https://www.who.int/emergencies/diseases/novel-coronavirus-2019/events-as-they-happen (Accessed 18 May 2020).

Worldometers (2020) Nigerian population [Online]. Available at www.worldometers.info/world-population/nigeria-population (Accessed 27 April 2020). 


\begin{tabular}{|l|l|l|}
\hline Constructs & Subtypes & Examples \\
\hline Contextual demands & Overload & Working overtime, many household chores, urgent care tasks \\
& Physical & Lifting weights, childcare, elderly care \\
& Emotional & Dealing with work stress, conflicts at home, disappointments \\
& Cognitive & Writing a report, multitasking, coordination of household \\
\hline Contextual resources & Social support & Managerial support, respect from friends, help from co-workers \\
& Autonomy & Control over work, planning leisure time, allocating home tasks \\
& Feedback & Supervisor evaluation, open communication at home \\
& Development & New work tasks, attending courses, participating in sports, \\
& opportunities & hobbies \\
\hline Personal resources & Physical & Physical energy, health, vigour, sleep, strength \\
& Psychological & Optimism, self-efficacy, mental resilience, focus \\
& Affective & Fulfilment, mood, empathy, gratitude \\
& Intellectual & Perspectives, skill, knowledge, experience, competence \\
& Capital & Time, money \\
\hline Outcomes & Production & Meeting deadlines, completing tasks, quality care tasks \\
& Behavioural & Absenteeism, turnover, availability at home, family protection \\
& Attitudinal & Commitment, satisfaction, wellbeing, relationship quality \\
\hline
\end{tabular}

Table 1: Highlights from the (W-HR) model

Source: Adapted from ten Brummehuis and Bakker (2012) 


\begin{tabular}{|c|c|c|c|c|c|c|c|c|}
\hline Pseudonyms & Age & Religion & Rank & Years employed & Employment status & $\begin{array}{l}\text { Type of } \\
\text { University }\end{array}$ & Number of children & Age of children \\
\hline Participant 1 & 40 & Christianity & Lecturer I & 9 & Full-time & Private & 2 & $3 \& 6$ \\
\hline Participant 2 & 50 & Islam & Senior Lecturer & 12 & Full-time & Private & 4 & $10,13,16 \& 20$ \\
\hline Participant 3 & 33 & Christianity & Lecturer II & 6 & Full-time & Private & 1 & 5 \\
\hline Participant 4 & 55 & Christianity & Lecturer I & 7 & Full-time & Private & 3 & $9,13 \& 17$ \\
\hline Participant 5 & 59 & Christianity & Lecturer I & 8 & Full-time & Private & 2 & $6 \& 10$ \\
\hline Participant 6 & 34 & Christianity & Assistant Lecturer & 4 & Full-time & Private & 1 & 3 \\
\hline Participant 7 & 28 & Christianity & Lecturer I & 9 & Full-time & Private & 3 & $4,7 \& 12$ \\
\hline Participant 8 & 52 & Islam & Senior Lecturer & 15 & Full-time & Private & 2 & $11 \& 16$ \\
\hline Participant 9 & 42 & Christianity & Lecturer II & 5 & Full-time & Private & Twins & 8 \\
\hline Participant 10 & 60 & Islam & Associate Professor & 15 & Full-time & Public & 3 & $12,15 \& 19$ \\
\hline Participant 11 & 47 & Islam & Lecturer 1 & 10 & Full-time & Private & 5 & $5,8,11 \& 14$ \\
\hline Participant 13 & 37 & Christianity & Assistant Lecturer & 4 & Full-time & Private & 2 & $8 \& 10$ \\
\hline Participant 14 & 64 & Islam & Professor & 17 & Contract & Private & Twins & 18 \\
\hline Participant 15 & 35 & Christianity & Lecturer II & 11 & Full-time & Private & 3 & $2 \& 5$ \\
\hline Participant 16 & 40 & Islam & Senior Lecturer & 9 & Full-time & Private & 2 & $9 \& 12$ \\
\hline Participant 17 & 25 & Christianity & Assistant Lecturer & 3 & Full-time & Private & 1 & 3 \\
\hline Participant 18 & 36 & Christianity & Lecturer II & 7 & Full-time & Private & 2 & $6 \& 10$ \\
\hline Participant 19 & 41 & Islam & Lecturer I & 6 & Full-time & Private & 4 & $2,4,7 \& 10$ \\
\hline Participant 20 & 65 & Christianity & Professor & 10 & Full-time & Private & 2 & $11 \& 17$ \\
\hline Participant 21 & 31 & Islam & Lecturer I & 6 & Full-time & Private & 1 & 9 \\
\hline Participant 22 & 50 & Islam & Senior Lecturer & 7 & Full-time & Public & 2 & $3,6 \& 11$ \\
\hline Participant 23 & 58 & Christianity & Lecturer I & 8 & Full-time & Private & 3 & $4,9,11 \& 16$ \\
\hline Participant 24 & 49 & Christianity & Lecturer II & 9 & Full-time & Private & 1 & 17 \\
\hline Participant 25 & 64 & Christianity & Associate Professor & 14 & Contract & Private & 2 & $12 \& 14$ \\
\hline Participant 26 & 39 & Islam & Lecturer I & 8 & Full-time & Private & 3 & $4,6 \& 9$ \\
\hline Participant 27 & 46 & Christianity & Senior Lecturer & 10 & Full-time & Private & 2 & $5 \& 10$ \\
\hline Participant 28 & 29 & Christianity & Assistant Lecturer & 3 & Full-time & Private & 5 & 4 \\
\hline
\end{tabular}

Table 2: Demographic data of participants 


\begin{tabular}{|c|c|c|c|c|}
\hline $\begin{array}{l}\text { Key themes (Effects of the } \\
\text { pandemic) }\end{array}$ & $\begin{array}{l}\text { Number of } \\
\text { participant } \\
\text { responses }\end{array}$ & $\begin{array}{l}\text { Approximated } \\
\text { percentages }\end{array}$ & Relevant theoretical dimensions of the (W-HR) model & Sampled excerpts \\
\hline \multirow[t]{2}{*}{ Career Stagnation } & 13 & 45 & $\begin{array}{l}\text { Imbalance between contextual demands (e.g. workload, } \\
\text { working time, home management) and personal } \\
\text { resources (e.g. employment gains - salaries, bonuses, } \\
\text { pay rise, financial stability). }\end{array}$ & $\begin{array}{l}\text { "The lockdown is affecting my } \\
\text { career prospects because working } \\
\text { from home with my children always } \\
\text { around is very challenging while } \\
\text { I'm also experiencing financial } \\
\text { strain as a result of the pay cut I } \\
\text { have to endure for now" }\end{array}$ \\
\hline & 11 & 40 & $\begin{array}{l}\text { Loss of contextual resources (e.g. meaningfully engaging } \\
\text { with academic research, suitability of home workspaces, } \\
\text { opportunities to attend career development agendas) }\end{array}$ & $\begin{array}{l}\text { "My research output is suffering } \\
\text { because writing papers at home } \\
\text { with distractions from my children } \\
\text { makes things difficult and stressful" }\end{array}$ \\
\hline Health Concerns & 17 & 60 & $\begin{array}{l}\text { Loss of personal resources (e.g. health, wellness, good } \\
\text { sleep, physical energy) }\end{array}$ & $\begin{array}{l}\text { "Unfortunately the pandemic is } \\
\text { creating more health challenges } \\
\text { particularly for us, working mothers } \\
\text { who feel extremely burdened..." }\end{array}$ \\
\hline Male Chauvinism & 28 & 99.9 & $\begin{array}{l}\text { Unfavourable macro resources affecting work-family } \\
\text { interface (e.g. patriarchy, masculine hegemony, gender } \\
\text { stratification) }\end{array}$ & $\begin{array}{l}\text { "The pandemic has excessively } \\
\text { increase male-group domination at } \\
\text { home making work-family } \\
\text { integration impossible for } \\
\text { professional working mothers" }\end{array}$ \\
\hline
\end{tabular}

Table 3: Researcher's data analysis 